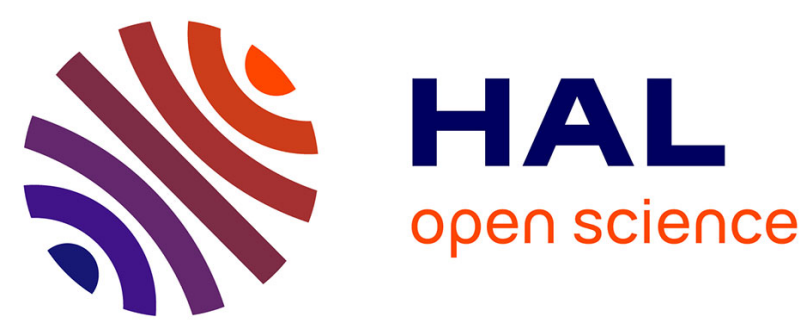

\title{
MECHANISM OF STEP COVERAGE FORMATION OF SiO2 FILMS FROM TEOS AND EFFECTS OF GAS PHASE ADDITIVES STUDIED BY MICRO/MACROCAVITY METHOD
}

\author{
Y. Egashira, T. Sorita, S. Shiga, K. Ikuta, H. Komiyama
}

\section{To cite this version:}

Y. Egashira, T. Sorita, S. Shiga, K. Ikuta, H. Komiyama. MECHANISM OF STEP COVERAGE FORMATION OF SiO2 FILMS FROM TEOS AND EFFECTS OF GAS PHASE ADDITIVES STUDIED BY MICRO/MACROCAVITY METHOD. Journal de Physique IV Proceedings, 1991, 02 (C2), pp.C2-55-C2-61. 10.1051/jp4:1991206 . jpa-00249773

HAL Id: jpa-00249773

https://hal.science/jpa-00249773

Submitted on 1 Jan 1991

HAL is a multi-disciplinary open access archive for the deposit and dissemination of scientific research documents, whether they are published or not. The documents may come from teaching and research institutions in France or abroad, or from public or private research centers.
L'archive ouverte pluridisciplinaire HAL, est destinée au dépôt et à la diffusion de documents scientifiques de niveau recherche, publiés ou non, émanant des établissements d'enseignement et de recherche français ou étrangers, des laboratoires publics ou privés. 
Colloque C2, suppl. au Journal de Physique II, Vol 1, septembre 1991

\title{
MECHANISM OF STEP COVERAGE FORMATION OF $\mathrm{SiO}_{2}$ FILMS FROM TEOS AND EFFECTS OF GAS PHASE ADDITIVES STUDIED BY MICRO/MACROCAVITY METHOD
}

\author{
Y. EGASHIRA, T. SORITA, S. SHIGA, K. IKUTA and H. KOMIYAMA \\ Department of Chemical Engineering, Faculty of Engineering, \\ The University of Tokyo, 7-3-1 Hongo, Bunko-ku, Tokyo 113, Japar
}

\begin{abstract}
The mechanism of $\mathrm{S1O} 2$ deposition by pyrolysis of TEOS at $973 \mathrm{~K}$ was studied by the micro/macrocavity method proposed previously by the authors. We analyzed the

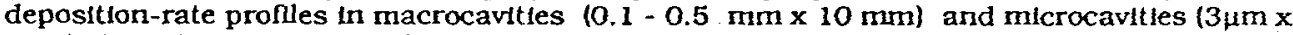
$2 \mu \mathrm{m})$. based on a model of diffusion and chemical reaction occurring simultaneously. Analysis of deposition-rate profiles under reduced pressure (2 Torr) and medium pressure (60 Torr) showed the existence of two kinds of intermediate species, a highly active one and low active cne. The effects of gas phase additives (NH3 or $\mathrm{H} 2 \mathrm{O}$ ) were also examined. Conformal depositions in microcavities were achieved by the addition of $\mathrm{H} 2 \mathrm{O}$ in this reaction system.
\end{abstract}

\section{1.-Introduction}

In various applications of CVD processes, control of the deposition rate profile is often an important subject. For example, in applications for VLSI industry, uniformity in deposition rates between wafers, within each wafer, and within micrometer-sized circult lines are required. To achleve such uniform-proflle deposition. the knowledge of reaction mechanism which distinguishes between gas phase reaction and surface reaction is indispensable, because distribution of intermediate species governed by gas phase reactions can cause nonuniform deposition profles.

The authors proposed a novel method for distinguishing gas phase reaction from surface reaction named "micro/macrocavity method" (1) which analyzes the deposition rate profiles in a macrocavity $(0.1-0.5 \mathrm{~mm} \times 10 \mathrm{~mm})$ and a microcavity $(3 \mu \mathrm{m} \times 2 \mu \mathrm{m})$, based on a model of diffuslon and reactions occurring simultaneously. Applying this method to deposition of SIO2 by TEOS pyrolysis at $1073 \mathrm{~K}$ under reduced pressure $(2$ Torr) indicated the existence of intermediate species formed in the gas phase (2). In this paper, the mechanism of TEOS pyrolysis at $973 \mathrm{~K}$ is studied extensively to understand the role of the intermediate species in the formation of step coverage. The important role of another intermediate species is indicated by varying the total pressure during deposition. The effects of the additives in the reactant stream on the film deposition mechanisms are also examined by the micro/macrocavity method.

\section{2.-Experimental}

The reactor was a quartz tube (I.D. $15 \mathrm{~mm}$ ) heated by a resistive heating. furnace with uniform temperature zone $120 \mathrm{~mm}$. A stream of N2 flowed through a bubbler to evaporate TEOS. Micron-sized trenches (depth $3 \mu \mathrm{m}$, width $2 \mu \mathrm{m}$ ) constructed on silicon wafers by normal lithographic procedures were used as microcavities. As depicted in Fig. 1, two strips of the same shape (10 mm x $10 \mathrm{~mm}) \mathrm{were}$ cut from a wafer and attached to one another with spacers placed between them. This artifact was used as macrocavity. 
All the deposition runs were carried out at $973 \mathrm{~K}$. Two serles of deposition experiments were performed in different pressure reglons. In low pressure CVD (LP-CVD) experiments, deposillons were carrled out under a total pressure of 2 Torr and a TEOS partlal pressure of 0.11 Torr. In the medium pressure CVD (MP-CVD), the total pressure was 60 Torr with a TEOS partial pressure of $1.2-1.6$ Torr. The effects of gas phase addittves were examined in the region of MP-CVD by adding 15 Torr of NH3 or H2O. After a deposition run, thickness profliles of S1O2 film along the reactor and inside the microand macrocavity were measured by SEM observation or by an optical method.

\section{3.-Results and Discussion}

\section{3-1.-Low pressure CVD (LP-CVD)}

Simulation of deposition rate profles in a micron-sized trench (or microcavity), assuming a single deposition species having a sufficiently long mean free path length, was made to determine the relationship between the sticking probability of deposition species $(\eta)$ and the step coverage quality. defined as the ratio of the film thickness at the bottom of the trench to that at the top (Tb/Ts) for a given shape of trench (Fig.2). An important feature of Fig.2 is that nonuniform deposition rate profiles can occur only in the case of a high sticking probability $(\eta>0.1)$.

Figure 3 shows the dependence of the step coverage quality at the center of a macrocavily on the width of the macrocavity (W) in LP-CVD. Surprisingly, the step coverage quality is dependent on the width of macrocavity (W). This means that there exist at least two deposition species and that one of them is a highly active species. This highly active species is responsible for the nonuniformity of the deposition rate profiles, and the change of the step coverage quality can be understood as the results of the change in the relative contributions of the highly active and less active species.

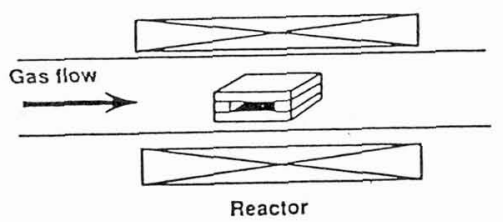

$0.1-0.5 \mathrm{~mm}$

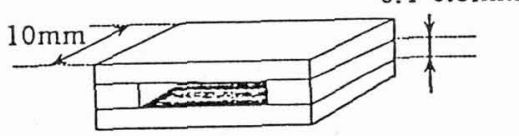

Macrocavity

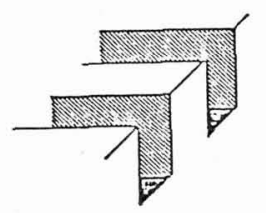

Microcavity

Fig. 1 Schematics of a micro/macrocavity

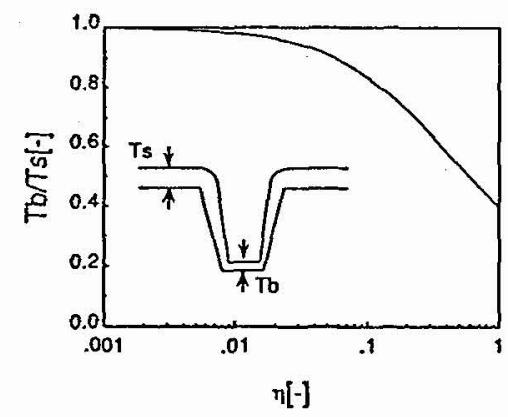

Fig.2 Relation between sticking probability of deposition species $(\eta)$, and step coverage quality (Tb/Ts). (simulation)

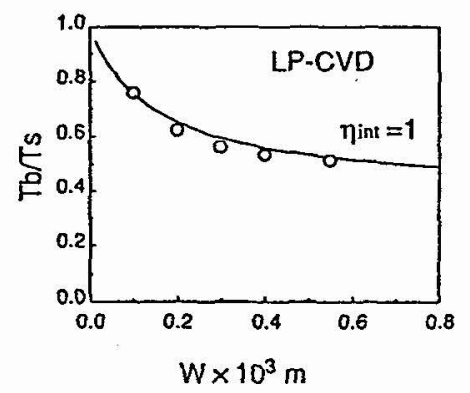

Fig.3 Dependence of step coverage of microcavitics ( $\mathrm{Tb} / \mathrm{Ts}$ ) ncar the center of macrocavities on the width of macrocavities, W. Solid line shows the result of curve fitting by Eq. 3 
The simplest reaction scheme to explain this result is as follows;

$\begin{array}{ccc}\text { TEOS } & \rightarrow & \begin{array}{c}\text { intermodiate } \\ \text { species }\end{array} \\ \downarrow & \downarrow \\ \text { film } & & \text { film }\end{array}$

In this reaction model, TEOS is a most probable candidate for the less activity species and some intermediate species, produced in the gas phase from TEOS, acts as the highly active deposition species.

Analysis of the profile inside the macrocavity provides good support for this model (Fig.4). A characteristic feature of this profle is a very steep proflle near the edge of the macrocavity and a completely flat proflle near its center. The reaction scheme proposed explains the flat proflle as a deposition of TEOS and that of the intermediate species produced inside the macrocavity. Contributions of these two reaction paths are evaluated separately by changing the width of macrocavity (W). The rate of direct deposition of TEOS is independent of $W$. On the other hand. the deposition rate of intermediate species is linearly dependent on $\mathrm{W}$ because the gas phase volume over the wafer surface where intermediate specles is produced linearly depends on w. A plot of the growth rate at the center of a macrocavity agalnst W (FIg.5) makes it possible to separate the contributions of direct deposition of TEOS and deposition of Intermediate species, according to Eqs. (1) and (2).

$$
\begin{aligned}
& \text { (fraction of direct deposition of TEOS) } \\
& \qquad \mathrm{X}_{\text {TEOS }}=\frac{1}{1+4850 \cdot \mathrm{W}} \\
& \text { (fraction of deposition of intermediate species) } \\
& \quad=1-\mathrm{X}_{\mathrm{TEOS}}=\frac{4850 \cdot \mathrm{W}}{1+4850 \cdot \mathrm{W}}
\end{aligned}
$$

Step coverage on the trenches located near the center of the macrocavitles is determined by the balance of these two contributions. This can be written as.

$$
\left(\frac{T_{b}}{T_{s}}\right)_{\infty \infty s}=\left(\frac{T_{b}}{T_{s}}\right)_{\text {TEOS }} X_{T E O S}+\left(\frac{T_{b}}{T_{b}}\right)_{\text {int }}\left(1-X_{\text {TEOS }}\right)
$$
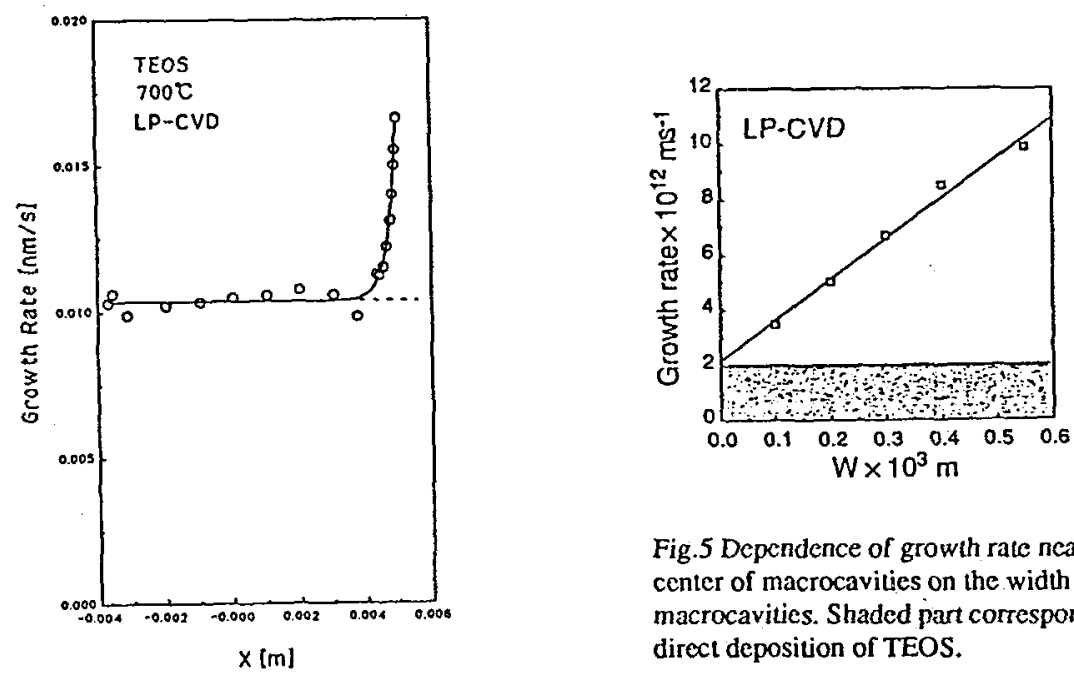

Fig.5 Dependence of growth rate near the center of macrocavities on the width of macrocavities. Shaded part corresponds to the direct deposition of TEOS.

Fig.4 Profiles inside the macrocavity in LP-CVD. Solid line shows the result of curve fitting by Eqs. 7,8. 


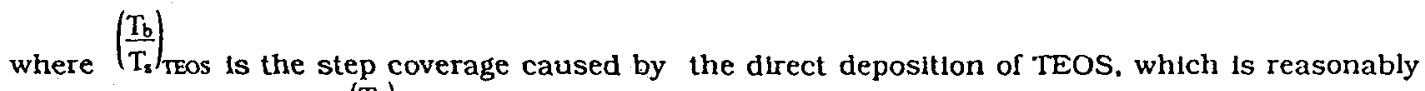
assumed to be unity. $\left(\frac{T_{b}}{T_{s}}\right)_{\text {mit }}$ caused by the intermediate species, is related to the value of $\eta_{\text {int. }}$ Substituting Eqs.1.2 into Eq.3 and comparing with the relatlonship shown in Fig.2, parameter fitting of $\eta_{\text {int }}$ to the data shown in Fig. 3 was attempted. The result is

$$
\eta_{\text {int }}=1 \text {. }
$$

The agreement of this value of $\eta_{\text {int }}$ with the near-edge profile of macrocavity was checked in the following way. The concentration level of intermediate species is governed by the production and consumption rates. Generally, the larger the volume-to-surface ratio, the higher the concentration level. The steep profile may be explained by the result of diffusion of intermediate species from the entrance, accumulated outside the macrocavity. followed by deposition. The conservation equation for intermediate species in excess of the pseudoequilibrium concentration determined by the volume-to-surface ratio of a macrocavity is

$$
D_{\text {in }} \frac{d^{2} C_{\text {int }}}{\mathrm{dx}^{2}}=\frac{2}{W} \mathrm{k}_{\sin t C_{\text {int }}}
$$

.where $x$ is distance from the center of a macrocavily, $D_{i n t}$ is a diffusion coefficlent of the intermediate species, $C_{i n t}$ is the excess concentration of the intermediate species, and $\mathrm{k}_{\text {sint }}$ is a surface reaction rate constant for the intermediate species which is directly related to $\eta_{\text {int }}$ by.

$$
\mathrm{k}_{\sin \mathrm{t}}=\frac{1}{4} \mathrm{~V}_{\mathrm{i}} \eta_{\mathrm{in}}
$$

where $V_{t}$ is a mean thermal velocity of the intermediate species. Solving Eq.(5) under the symmetric constraint for this reaction field, Eq.(7) is obtained.

$$
\begin{aligned}
\text { growth rate } & =\mathrm{k}_{\text {sint }} C_{\text {int }} \\
& =\mathrm{K} \cosh \left(\sqrt{\frac{2}{W} \frac{k_{\text {sint }}}{D_{\text {int }}}} x\right) \\
& =K \operatorname{cosin}\left(\sqrt{\frac{V_{t} \eta_{\text {int }}}{2 W D_{\text {int }}}} x\right) .
\end{aligned}
$$

With an assumption that the values of $V_{t}$ and $D_{i n t}$ are equal to those of TEOS,

$$
\sqrt{\frac{V_{\mathrm{t}} \eta_{\text {int }}}{2 W \cdot D_{\text {int }}}}=6000 \mathrm{~m}^{-1}
$$

Result of curve fitting using this value is shown in Fig.4. The very steep proflle near the edge of a macrocavity is reasonably explained as the result of the high activity of intermediate species $\left(\eta_{\text {int }}=1\right.$ ).

\section{3-2. Medium pressure CVD (MP-CVD)}

A deposition rate pronle inside a macrocavity under the medium pressure CVD condition is shown in Fig.6. In contrast to the steep profiles occurring in the LP-CVD, there are shallow profiles in MPCVD. This profle is not due to the highly active intermediate species, which was the origin of the steep profile in the LP-CVD. Because the increase of the pressure reduces the diffusion coefficient $\left(D_{\text {int }}\right.$ ). resulting in a large argument of the hyperbolic cosine function of Eq.7, the deposition rate profiles corresponding to this highly active species should be much steeper than in the LP-CVD. In practice, the slope may be too steep to analyze. The question then arrives, does this profile correspond to the concentration profile of TEOS? The following analysis shows that this profile is not the result of the TEOS concentration profle.

The growth rate of $\mathrm{SIO} 2$ which is the sum of various reaction paths divided by the concentration of

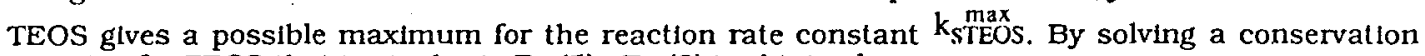
equation for TEOS that is similar to Eq.(5), Eq.(9) is obtained. 


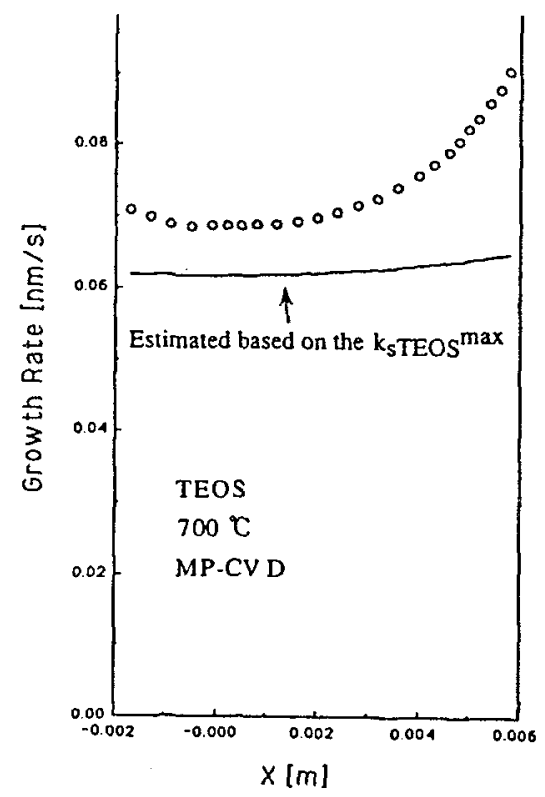

Fig.6 Profile inside the macrocavity in MP.CVD. The width of macrocavity is $0.3 \mathrm{~mm}$.

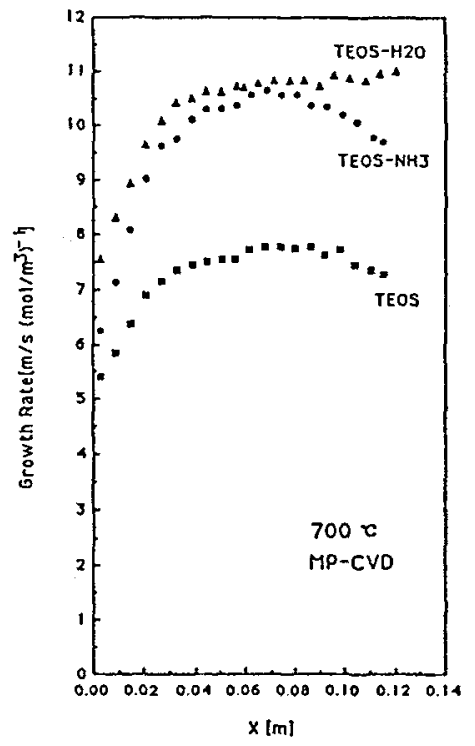

Fig. 7 Growth rate profiles along the reactor tube for TEOS, TEOS $+\mathrm{H} 2 \mathrm{O}$, TEOS $+\mathrm{NH} 3$ reaction system. Growth rate is normalized inlet concentration of TEOS.

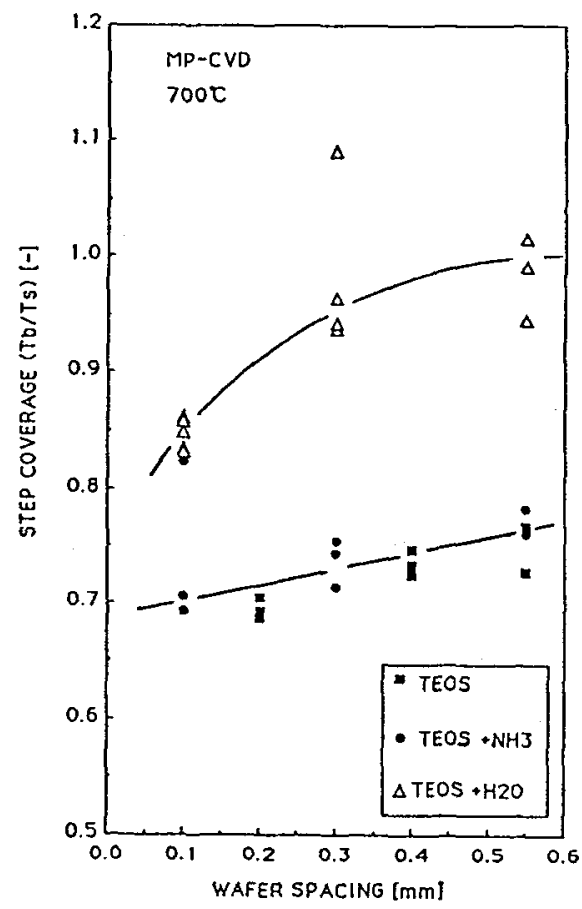

Fig. 8 Dependence of step coverage of microcavity near the center of macrocavities on width of macrocavily $W$ for TEOS, TEOS $+\mathrm{NH} 3$, and $\mathrm{TEOS}+\mathrm{H} 2 \mathrm{O}$ reaction system. 


$$
\text { growth rate }=K \cosh \left(\sqrt{\frac{2}{W} \frac{k_{S T E O S}}{D_{\text {TEOS }}}} x\right)
$$

Substitution of the value of $\mathrm{k}_{\mathrm{sTEOS}} \max _{\text {and }}$ the values of $\mathrm{W}$, and DiEos into Eq.(9) determines the argument of the hyperbolic cosine function.

$$
\sqrt{\frac{2}{W}} \frac{k_{\text {STEOS }}}{D_{\text {IEOS }}} \leq 56.6 \mathrm{~m}^{-1}
$$

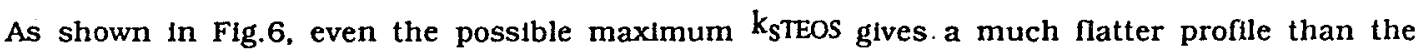
experimental one. Consequently another intermediate species characterized by a lower activity than the highly active intermediate species previously discussed should be responsible for the profile observed.

The low activity of the second Intermediate species logically predicts a conformal step coverage. But surprisingly, the values $\mathrm{Tb} / \mathrm{Ts}$ of microcavities near the center of a macrocavity are actually less than unity (Fig.8). This means significance of the deposition of highly active species. This fact suggests the existence of a reaction to convert a low active intermediate species to a highly active one.

\section{3-3 EIfects of gas phase additives.}

Growth rate proflles along the reactor tube for TEOS. TEOS $+\mathrm{NH} 3, \mathrm{TEOS}+\mathrm{H} 2 \mathrm{O}$ systems are shown in Fig.7. Addition of $\mathrm{NH} 3$ or $\mathrm{H} 2 \mathrm{O}$ accelerates the deposition of TEOS, and it should be stated that $\mathrm{TEOS}+\mathrm{NH} 3, \mathrm{TEOS}+\mathrm{H} 2 \mathrm{O}$ systems generate significant amounts of powder. Although the accelerating effect of $\mathrm{NH} 3$ and $\mathrm{H} 2 \mathrm{O}$ seems equivalent in Fig.7, the micro/macrocavity analysis reveals the difference between the effects of these two additives. As shown in Fig.9, the deposition rate profiles inside the macrocavities in the TEOS $+\mathrm{NH} 3$ system are similar to that for TEOS. In contrast, profiles in TEOS $+\mathrm{H} 2 \mathrm{O}$ system are much steeper than the other systems. Instead, flat deposition rates near the center of macrocavities are greater than the other systems. The step coverage quality of microcavities more clearly shows the difference between the additives. Deposition of $\mathrm{SIO}_{2}$ from the TEOS $+\mathrm{H} 2 \mathrm{O}$ system yields a conformal profile, while TEOS $+\mathrm{NH} 3$ system is not distinguishable from TEOS system (Fig.8).

\section{4.-Summary}

The mechanism of SiO2 deposition by TEOS pyrolysis was studled by the micro/macrocavity method. The existence of two intermediate species, a highly active one and less active one, was indicated by comparing the deposition rate profiles inside the macrocavities with LP.CVD and MPCVD. Nonconformal step coverage observed inside the microcavitles at MP-CVD suggests that the low active intermediate species changes to a highly active one. Addition of $\mathrm{NH} 3$ and $\mathrm{H} 2 \mathrm{O}$ in the gas phase similarly accelerates the deposition rate but differently influences the step coverage quality. Particularly, an improvement of step coverage quality was achieved by the addition of $\mathrm{H} 2 \mathrm{O}$ in the gas phase.

\section{5.-Acknowledgment}

The authors greatly appreclate the help of Dr. K. Sugawara, Hitachi VLSI Engineering Corp., in supplying the fabricated silicon wafers.

\section{6.-References}

/1/ KWatanabe and H.Komiyama; J.Electrochem. Soc. 137(1990)1222.

/2/ Y.Egashira, K.Ikuta, K. Watanabe and H.Komiyama: Proc. of 11 th Int. Conf, on CVD (CVD XI); Seattle, WA, (1990)418 

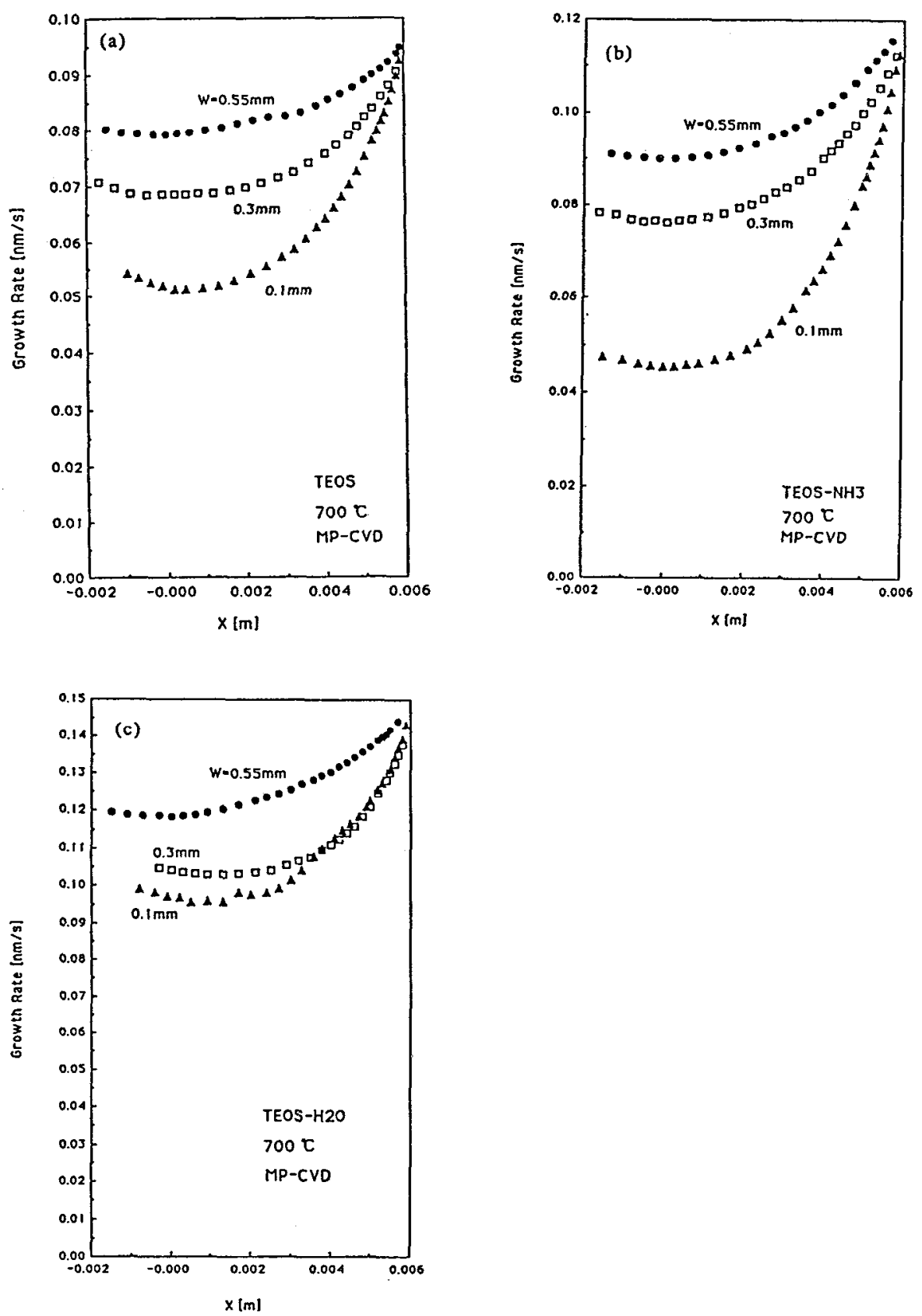

Fig. 9 Growth rate profiles inside macrocavities for TEOS

(a), TEOS+NH3 (b), and TEOS+H2O (c) reaction system. 